\title{
Developing a Digital Currency from an Islamic Perspective: Case of Blockchain Technology
}

\author{
Ibrahim Bassam Alzubaidi ${ }^{1}$, Adam Abdullah ${ }^{1}$ \\ ${ }^{1}$ IIUM Institute of Islamic Banking and Finance, Malaysia \\ Correspondence: Ibrahim Bassam Alzubaidi, IIUM Institute of Islamic Banking and Finance, Malaysia.
}

Received: August 24, 2017

Accepted: September 7, $2017 \quad$ Online Published: September 29, 2017

doi:10.5539/ibr.v10n11p79

URL: https://doi.org/10.5539/ibr.v10n11p79

\begin{abstract}
Numerous studies ranging from concept papers and reviews were conducted on the matter of blockchain and digital currencies. However, those two areas are not well researched due to its being a new area of research. Furthermore, the research on blockchain applications in the Islamic financial system precisely the potential of digital currency in providing a better alternative to current fiat money system which will be the scope of this article. The aim of revolves around exploring the potential and capability of introducing a digital currency that fulfills the Islamic law (Shari'ah) functions of money and provides a more stable currency than fiat money. The method used for analyzing this object includes a library research on related topics that helps understanding the functions of money and digital currencies and study of several cases that can assist in fulfilling the objectives of this paper in introducing an Islamic digital currency through detailed research of Islamic theory of money and civilization as well as the developments of blockchain, our findings point towards the ability of introducing a Shari'ah-compliant digital currency if all the issues on validity are addressed and resolved. However, the area of digital currencies and blockchain requires further research from a Shari'ah perspective to facilitate a better understanding on the topic.
\end{abstract}

Keywords: digital currencies, Islamic finance, functions of money, Islam, blockchain

\section{Introduction}

Several decades ago, Islamic finance was introduced in a more official way and since then, it showed an enormous growth prospect. Applications of Shari'ah compliant financial and banking services proved success since its introduction drawing several efforts into regulating its activities to serve the best interest of participants in the industry. Islamic banking and finance framework is drawn from the revealed knowledge of the primary sources in Islamic consisting of Qur'an and Sunnah of the Prophet Mohammed (SAW). Hence, its applications are permissible unless it is proven to contradicts Shari'ah. In general, the Islamic financial system differs from its conventional counterpart since the first prohibits any activities that involves the three elements of interest (Riba), Ambiguity (Gharar) and Gambling (Maysir). These three elements should not be presented in any contract or transaction in Islamic banking and financial industry or in Islamic economic system. Money and the concept of currencies is considered of the main elements building a financial system since it is used as a payment system to settle transaction in the financial system as well as everyday life. Nowadays, our currencies are based on the concept of paper money in which the central bank print it and control its circulation in the economy through what is known as a monetary policy.

The real issues of fiat money started rising particularly after the dissolvement of Bretton woods agreement that used to peg the U.S currency to the price of Gold. Since 1973, the paper money issued holds no intrinsic value rather than it is backed by the trust of the public in their government ability to control its circulation to achieve economic stability and prevents high inflation causing the currency to devaluate. However, until this day, fiat money proved its inability to be a store of value which is one of the primary functions of money. This issue leads to questioning the ability of paper money to be considered compatible to Islamic requirements in a currency. in addition to that, Islamic recognizes only commodities with an intrinsic value as a currency such as gold and silver which paper money does not hold such attributes leading several scholars to deem it to be non-compliant to Shari'ah. Furthermore, several literatures discussed the effect of fiat money on the economy and the financial system leading to uncontrolled inflation and financial crises. issue Since the start of technological era, several innovations have changed the way we perceive things. 
One of the major innovations that is believed to be changing the economy and the world is blockchain. Blockchain first appearance was in a paper issued by Nakamoto (2008) that was used as a public ledger for the famous currency called "bitcoin". since then, blockchain application extended further than being a ledger for currencies and impacted several aspects of the economy and financial services sector. The advantage of blockchain in digital currency can extend to developing a more transparent and secure payment system. its efficiency and ability to be used by everyone made its application to be reachable by many unbanked individuals leading more people to be included in the economic and financial activities. Henceforth, we argue that digital currencies could serve the world and the economy more than the concept of paper money.

However, there are still some issues concerning digital currencies that hinders it from being a currency that is compatible with Islamic requirements for a currency, the main issue of digital currency that it still miss the ability to provide a clear intrinsic value or a physical existence which is required by Shari'ah. Hence, the object of this paper circles around investigating the abilities of digital currencies and the concept of blockchain to serve as an Islamic digital currency. to understand how digital currencies can serve as an Islamic digital currency. a historical investigation on the origins of money in Islam is to be done. Hence, since Gold was the main currency within the Islamic civilization, studying its salient features will produce the features needed to produce an Islamic currency. further study is done to uncover some of the issues in digital currencies that hinders its applications to comply with Shari'ah and find solutions from current cases on the topic of digital currencies.

\section{Literature Review}

The concept of money has been in a circle of discussions in the past decades particularly after the introduction of trust based fiat money and leaving the gold standard behind. Money is considered to have several definitions but circle around a similar concept. According to Lim \& Sriram (2003), The question of definition of money has been a subject of disagreement for many years and several economists proposing different financial assets to be considered as money with no single definition to be universally accepted. From an Islamic perspective, money is considered as medium of exchange and measurement of economic value. However, it is not a type of commodity that can be traded and expect a return of it without engaging it in a productive activity (Omar, 2011). It is believed that the current monetary system is using the wrong type of monetary instrument causing several issues in the economy. According to Greco (2009), The current system is providing a wrong type of economic growth since it is out of control and in the wrong places generating greater gap of power and wealth that is harming the lives of people. The focus on the topic of Gold comes mainly from several arguments that discusses the importance of gold and having a currency of intrinsic value and how it can prevent and keep the economic safe from crises other issues as inflation. Other researchers believed that introducing an Islamic Gold Dinar (which is a gold currency) in the meantime has no practical value since it cannot control the inflation level and may cause a global unshared ambiguity (Cizakca, 2011). In the past decades, most of the literature focus went towards Gold as a better alternative to fiat money since few of practical alternatives are there to use. According to Chapra (1983), The monetary policy in Islamic Economic helps in achieving socio-economic goals which Islamic placed emphasis upon.

It is argued as well that the current monetary policies are based on conventional monetary theory that have several flaws because it includes secular reasoning where the other Islamic analysis model is based on Shari'ah and not man's reasoning alone (Abdullah, 2016). Hence, it is important to look for alternatives that serve the Islamic functions of money better than the fiat money such as what is known as alternative currencies. Alternative currencies can be found in several regions and with unique features depending on the environment and purpose it serves. The highlight of these currencies can be seen as digital currencies. it is claimed that bitcoin (and blockchain based currencies) promise capacity to solve many concerns such regulatory institutions influence and interpersonal trust (Maurer, Nelms \& Swartz, 2013). The underlying concept of digital currencies known as blockchain can be described as follows "blockchain consists of three main, complementary parts: a shared state, a set of rules for updating state via blocks and a trust model for timestamping." (Williamson, 2015). From what is tracked, blockchain is a type of mutual distributed ledgers and its function allows user to track, record and verify all the transactions in network to ensure its validity and security. It is hence a decentralized database. In the case of blockchain of Bitcoin, it is a cryptographic ledger shared among all the users on the network to verify transactions and add them to a block of other chained transactions to ensure the integrity of transactions and avoiding issues such as double spending (Mainelli \& Smith, 2015).

The Concept of applying Blockchain and relevant technologies to establish a well-developed and protected digital currency can be of a major value to discover new opportunities or enhance current features of the economy and monetary policies. However, it is still a viable issue of that current digital currencies is fully decentralized in which government does not look to it in a promising way since it cannot be manipulated to 
control certain economic outcomes. The case of virtual and digital currencies is that they cannot be considered as a legal tender by the monetary authorities which created several challenges such as its interaction with the real economy, protecting the consumer from any issues associated with these currencies and crimes and fraud that happened by using these currencies since it is not monitored or properly regulated by a suitable monetary regulation (Zahudi \& Amir, 2016). Hence, it might be a kind of opportunity to look the potential of regulating these currencies and their respective payment technologies. It may look like it defeats the purpose of decentralized currencies but it still can be of a massive potential to regulate it to a certain degree to protect the interest of the public.

When bitcoin is compared to gold, several similarities were observed and recent discussions proposed that bitcoin carry the responsible features of gold and might be a more practical alternative to modern currencies than gold. Haubo and Dyhrberg (2016) compared as well the difference ability of Gold, Bitcoin and USD in risk management and concluded that bitcoin is classified between gold and USD. It seems that the features which gravitates people towards physical gold or to digital currencies (Bitcoin as example) to be closely related in several aspects.

It was noticed that the literature of Bitcoin and Digital Currencies are rare when it comes to its development and concept under the Islamic financial and banking system in general. The reason may entail the ambiguity surrounding bitcoin and other relevant digital currencies and if they fit the criteria of being an Islamic currency which there isn't that much of literature that discusses its nature and Islamic requirements regarding it. according to a paper by Singhal and Rafiuddin (2014), it discussed that bitcoin "roughly" fits the requirements to be defined as money in Islam since is it abundant, freely obtainable, and durable as well. they argued that with proper control, digital currencies can serve as a good alternative and be compatible with the teaching of Islam. The issue of literature is described by Evans (2015) "IBF is still a work-in-progress. Disagreement continues among proponents and outside observers concerning the distinction between what is permitted (halal) and what is forbidden (haram) under different interpretations of Islamic Law (Shari'ah). Adding to the confusion is the desire of many Islamic banks' executives and customers to integrate those banks into the global banking and financial system". It is discussed as well by (Zahudi \& Amir, 2016) that electronic currencies are considered nowadays as a type of fiat money in which some of the views accepted it to be a medium of exchange despite the controversial arguments on fiat money and its comparison to gold and silver. This article will aim towards investigating the ability of Digital currencies and its blockchain systems to be integrated as an Islamic currency in which if it is applicable to fit the criteria of Digital currencies into Shari'ah requirements regarding functions of money and solving current issues hindering its progress towards that goal.

\section{Methodology}

The primary objectives are to identify and research specific aspects on digital currencies and the blockchain to identify its potential, build a comparison to other options and find some ways to integrate into an appropriate model that can be compatible to Islamic monetary system. several analyses are sought to define the current flaws existing in digital currencies and what are the solutions available to solve these issues. Hence, the methods used will follow a library research which will seek to identify the level of digital currency compatibility with Islamic practices and issues revolving around the topic. Furthermore, this paper will pursue a case study involving specific applied cases that attempted to address and solve some of the issues presented in digital currencies from different angles. Hence, providing a comprehensive image on how integrating these cases together can help in developing an Islamic digital currency model. Case study research assist in targeting a specific phenomenon to further explain it within its real-life context. The design of this paper aims to investigate several historical cases as well to make a generalized conclusion on this topic. Even though this is a qualitative research, an empirical evidence might be presented from other literature to provide a better conclusion on the topic since a topic of monetary and economic impact such as digital currencies must be reflected in empirical and theoretical evidences. Since the goal of this research is heading for a relatively new area of research in which two issues must be considered. First, is that Digital currencies and blockchain development is a bit of new research topic especially after the development of the world's most known digital currency Bitcoin. therefore, there are still several ideas and issues to be addressed in specific regarding this topic. Furthermore, Islamic perspective on Digital currency is still an under-developed area where not much of examination and research is done on it. for both issues, choosing a case study and library research methods seems more appropriate because the emphasis should be aimed towards building a better understanding on the topic rather than observing the awareness on it in which it is not expected to yield a better understanding towards developing digital currencies from and Islamic Perspective. 


\section{The Islamic Monetary Theory}

It seems that the theory of money and its origins goes back to more than what is historically remembered. Long before the concept of money, the barter trading system existed in which people trade commodities they have for commodities they need. However, in a basic sense, it is easy to realize that such concept does not carry much efficiency since it is not easy to match the gap between the commodities available and commodities needed which is called a double coincidence of wants. Henceforward, the concept of money was introduced to solve these issues that existed in the barter trading system. Mankind used several things ranging from shells, stones, metals such as gold and silver and reaching to the current monetary system known as the fiat money.

However, In the modern societies, fiat money does not represent a real value in its own design rather than a mere unit of account to represent the value of commodities and it is quantity is supplied and controlled by the central bank of each country in which the bank controls it through monetary policies to achieve economic stability. However, it seems different from some of the past units used as money since assets such as gold and silver were used as money and carried an intrinsic value it is content and its existence is limited in which it cannot be produced on demand comparable to the fiat money existed in the modern economic system. Henceforth, the need for a medium of exchange with certain functions to facilitate trading established and carried specific functions which are mainly categorized under three main aspects: medium of exchange, unit of account and to store value. Money had other criteria with time that made it a proper medium of exchange such as it measurability, durability, mobility, and divisibility which made it easier to simplify dealings.

Fiat money nowadays seem to carry controversial resolutions between Islamic jurists. The first opinion goes towards the resolution that fiat money is not Shari'ah compliant since it creates purchasing power value from nothing and with the increase of its supply follows an inflation and loss of value of currency leading to other harmful socio-economic problems such as poverty and wealth gap. The other opinion factors fiat money to be Shari'ah compliant since the central bank issuing the currency follows the objectives of government and it can control and preserve its value. They argue that even that fiat money is not of convenience, it still serves its objectives acting as money (Kamar et al, 2016). The Islamic fiqh academy of the Muslim world league issued a Shari'ah resolution regarding the nature and usage of paper money. It concluded that paper currency is an independent form of money and the rules applying to gold and silver apply to it as well. in resolution 9 D/3/07/86, the OIC Fiqh Academy decided that paper currency is a legal tender that have full qualities of a medium of exchange and the rules applying to gold and silver are applied to it.

Despite the controversial issues of Muslim scholars on fiat money, there are still so many issues attributed to it that makes lose its value and trustworthiness overtime. Abdullah (2016) argued under several examples that fiat money is merely backed by deb. The following table represents the monetary balance sheet of the Malaysian Ringgit as at 31sth Dec 2014

Table 1. Monetary Balance sheet of the RM as at $31^{\text {st }}$ Dec. 2014

\begin{tabular}{llllr}
\hline Assets & \multicolumn{4}{c}{ Liabilities } \\
\hline Gold & 5.2 & BNM Currency & 68.2 & \\
IOUs to Banks & $1,548.6$ & & Bank Deposits & $1,485.6$ \\
& & $1,553.8$ & M3 & $1,553.8$ \\
\hline
\end{tabular}

Source: Abdullah (2016)

As represented in Fisher equation:

$\mathrm{MV}=\mathrm{PY}$

it can be clearly seen that more supply of money (M) will increase the general prices which means more of (P) compared to Output $(\mathrm{Y})$ leading to an inflation which is basically more money chasing the same amount or fewer goods. When it is measured by the U.S dollars, it is noticed that the U.S dollars is losing its value overtime. A measure of this observation can be monitored by using an inflation tracker which despite the initial fluctuation, the U.S dollars kept losing is value due to inflation until this day. 


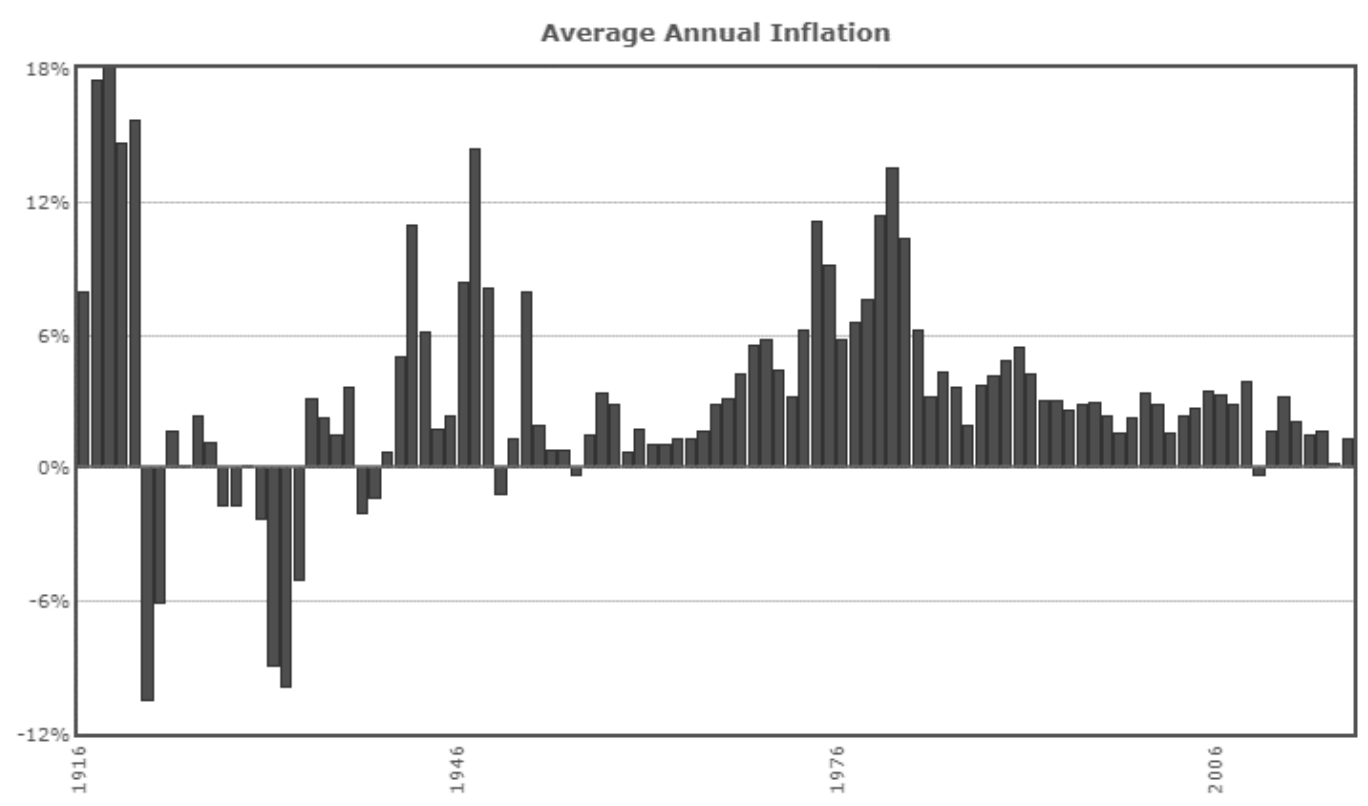

Figure 1. USD annual inflation rates

It is discussed by many that from an Islamic perspective, Fiat money does not fall in line with Maqasid al-Shari'ah due many factors even though some scholars may allow its usage for reasons of necessity. According to Meera \& Larbani (2009), the seigniorage of fiat money is considered a mere Riba and commodity monies such as gold and silver are Shari'ah compliant and goes in line with its objectives. In the past decades, new innovations from the development of digital currencies that are based on a more solid foundation of supply and store of value is giving a sign to a better development of a more stable currency options that are immune to inflationary effects and market manipulation. Digital currencies particularly the ones based on blockchain technology proved to supply a better mechanism for money supply, inflation control and succeeded in achieving other socio-economic objectives such as accessibility to financing and transparency.

\section{The Supremacy of Gold as an Islamic Currency}

When it comes to the definition of Islamic monetary theory, it seems that the arguments presented by classical Muslim scholars on the Islamic theory of money is consistent contrasting to the opinion of modern scholars (Abdullah, 2016). However, classical scholars favored gold and silver as an Islamic currency. Ibn Khaldun mentioned the functions of gold and silver as well in his book "Muqaddimah" as money "God has created the two metallic stones of Gold and Silver as a value for everyone to use in trading." Furthermore, AL Ghazali mentioned in his book Revival of Religious Science that "God Almighty created them to turn them between hands, and to be a judge between money with justice, and to another wisdom, which is to beg them to all other things, because they are dear in themselves, and have no purpose in themselves, and attributed them to all other things as one proportion.". In which he indicates that the currency cannot be used as a commodity traded for a price but as a medium of exchange only. It is hence seen that controversial to modern Islamic scholars, classic scholars insisted on using Gold and Silver as a currency and treated it as a pure medium of exchange and has no value which eliminates the concept of earning interest on it under the justification of time value of money. Gold seems to hold an immense value as a currency on its own for reasons beyond the concept of it being a valuable currency in Islamic history. Gold has been in circulation as a money even before the Islamic civilization. Furthermore, several analyses that compared gold to a fiat currency showed it superiority over the latter one. According to Abdullah (2013), the nominal price of gold in the United states acted as a hedge against inflation during the time of fiat standard in the U.S particularly between 1971-1979 and then the gap widens a bit from 1990 forwards.

\section{Viability of Developing a Shari'ah Compliant Digital Currency}

With the blockchain and Digital currencies becoming more known to individuals by the day, more literature is getting published with concepts that is signaling a comprehensive transformation on several aspects of life that includes political, social, and financial aspects with countless opportunities and solutions to existing problems. Aside from it being the core concept of digital currencies, it helped transform the financial system by giving it a 
better tool to integrate more integrity, transparency, and trust in it through the nature of Blockchain. The potential of digital currencies and blockchain is seen to be enormous. However, most of the literature that discusses implementing are pursuing the easier means of claiming that bitcoin and its payment system is Shari'ah compliant since it is better alternative than fiat money and under the rule of necessity. This argument holds truth to some extent since fiat money in its core value does not hold complete compliance with Shari'ah. However, bitcoin and conventional digital currencies still have some issue in compliance with Shari'ah mainly with Digital currencies holding no physical intrinsic value. Through Islamic history, Islam recognized commodities with intrinsic physical value only to be considered as money. and the second issue is regarding its practicality in today's societies where governments requires full control over the monetary supply to control economic conditions and keep it stable.

The authenticity of blockchain to be following Sharia' $h$ in brief can be discussed by inspecting if it contains any elements of prohibition in Islam. From previous discussions on blockchain, it is known that blockchain security include public key cryptography and follow a decentralized network approach instead of one server to record and verify transactions. The argument presented here is that in its concept and content, the concept of blockchain consists of computational and mathematical applications with no prohibited elements within its content. Furthermore, it does serve to eliminate prohibited elements such as Gharar (ambiguity) from transactions since its verification process is strong and transparent for all participants on the network.

The first issue concerning digital currencies is in its being a fully decentralized currency where no one can control its supply or verification process. Governments nowadays are proposing some ideas to include digital currencies such as blockchain within specific regulations to promote its development. However, most of governments are discouraged to promote it and even some rendered its trading to be considered as a legal activity The fear from allowing bitcoin and other digital currencies can be due to several elements. The governments are known to control the supply of paper currency in the economy through what is called "Monetary Policy" where money injects money or withdraws it from the economy to influence spending and investing resulting in more jobs and stabilizing inflation. The case if slightly different in the case of digital currencies adopting blockchain technology. Blockchain verifies all the transaction through miners consisting of computers solving complex mathematical algorithms to verify transactions and avoid double spending issues. Hence, banks are not needed to verify these transactions and cannot control the supply of digital currencies which seems to cause an issue for governments. According to Zahudi \& Amir (2016), "Virtual currency is still a largely uncharted and unsupervised area, and so far, no protections are likely available to the consumers that become involved with virtual currency if something goes wrong".

In the past couple of years, one of the interesting ideas were introduced by Danezis \& Meiklejohn (2015) which is called "RS Coin". The aim of this concept is to introduce some centrlization in the currency specifically in the process of generating money and verifying transactions to achieve best objectives combining advatnage of cryptocurrencies and stability of proper government control. Thier paper introduces an altenrative to bitcoin miners named "mintettes". However, they serve a similar object as miners which is maintaining the transaction ledger but they use different approach. Miners verify transactions through solving computationally difficult tasks where mintettes are authorized from the central bank to collect and maintain transactions in ledgers.

The second point regarding developing a a digital currency from an Islamic perspective revolves around the issue of digital currencies not having an intrinsic value compared to commodity money such as gold and silver. Several literatures may have argued that the mining process (in the blockchain) is creating the value for the bitcoin and digital currencies and since there is an effort in issuing the currency, it holds a value for that currency. However, we still cannot find a physical existence of that currency that backs it up and hold its value in the real world which still cause an issue in the definition of money from an Islamic perspective.

One of the solutions can be observed through attaching a physical commodity to backup digital currencies in the real world. To observe both requirements of having an intrinsic value for a currency and solve existing issues presented in the digital currencies such the volatility of its value over brief period, Gold can be observed as a decent commodity to be the backup physical existence of Digital currencies. This move will solve two key issues in digital currencies, first is the volatility of digital currencies prices since the gold prices are much more stable. Second is establishing a clear physical existence to the currency to back it up which will not allow the currency prices to be manipulated as seen in the fiat monetary system. Other important objectives will be achieved like trust in the currency. People are expected to gain trust in such a currency much faster than normal digital currencies since it is backed by gold which the public trust that it will preserve its value over time.

In May 2017, a technology company in Dubai called "One Gram" has issued the world's first gold backed digital 
currency. It is like bitcoin since it was created using the blockchain technology and each coin is backed by one gram of Gold. According to their website (One Gram), they collaborated with a gold trading company "Gold Guard" and started an initial coin offering consisting of 12,400,786 coins. One of the salient features is its stability since its linked with gold which sets a floor for the price of the coin that equals the price of Gold (1g). the currency grows in value since $70 \%$ of transactions fees will be reinvested to purchase more gold to increase the amount of gold backing up every coin in which the owners will share the profit from it.

Lastly, digital currency should be examined to see if it can achieve objectives of Islamic Law (Maqasid al-Shari'ah). Islamic Law (Shari'ah) listed 5 main higher objectives to be protected and preserved. One of the objectives is recognised as Preserving Wealth (Hifzal-Mal). There are several ways of preserving wealth in Islam. Wealth in Islam can be preserved through pursuing work and earning through permissible transactions and trading activities. Harmful activities such as theft, ambiguity, gambling, and interest are prohibited since it leads to destruction of wealth. Hence, involving in any activities that destroys wealth is prohibited. furthermore, adopting a currency that loses its value over time leads to the same conclusion of wealth destruction and any currency that loses its value over time does not serve the function of money as a store of value. Hence, the way fiat money is created through the debt and fractional reserve system not only will oppose the objectives of Shari'ah but cause a move away from it (Meera \& Larbani, 2006). By examining a digital currency that is modified to according to the cases that were discussed, it will be assumed to achieve the objective of preserving wealth since its creation is not based on debt or fractional reserve system which will protect it from losing its value especially if it is linked to a stable physical commodity such as Gold. It is also secure and transparent which will lead to elimination of any ambiguous or harmful activities. Transparency will also make the central bank clearer on its policies in creating more currencies and it will be constrained to the actual physical intrinsic value of it.

\section{Recommendation}

More research is still needed in several areas concerning blockchain and digital currencies. Blockchain and its application is considered a new niche that needs more literature consisting of analyzing flaws and issues with applying it in today's economy and other related areas as well as producing new concept papers that will provide more ideas or solve current issues in blockchain or the how the blockchain will solve existing complications occurring in the global economy and financial sector. Various types of literature on concepts applied by blockchain to several sectors such as insurance, banking and financial sectors showed an impressive potential of such technology but it is still under researched and needs more focus. The second area is digital currencies. This area needs further understanding and research on its role in developing payment systems and the current monetary policies.

When it comes to practitioners' role in developing the concept of blockchain and digital currencies, several roles are needed. First is learning more on the literature providing more concepts every day on blockchain and digital currencies. The next step would be willing to invest in such startups since it will provide more interest in researching if the industry is well invested in and promotes for more innovations. The gap between capital and ideas are causing a significant proportion of great ideas to stay on paper where it could change our perspective on economy and finance. Managers should be involved in following the advancement in such technologies since it is making new jobs with countless benefits to the market. Being well connected to the literature makes moving new ideas to practice an easier task creating more innovative environment in the market since one of the biggest challenges is the gap between theory and practice. In hope of that this research will assist in pledging more effort into developing more concepts on digital currencies, blockchain innovations and integrating Islamic values in them.

\section{Conclusion}

The past few decades have shown a comprehensive involvement in a new era of technological advancement. Those innovation have changed the perception of how economy and the world is perceived. Most of the literature are focused on the potential of blockchain in transforming the economy specifically the banking and financial sector. Blockchain promises several features including transparent, trust less and efficient environment for all types of economic and financial activities. However, this paper focused on the concept of blockchain in the development of the monetary system particularly currencies. This research investigated the development and potential of digital currencies backed by blockchain in transforming how currencies are perceived. To be more specific, this paper aimed into exploring the compatibility of developing a digital currency that is compatible with the rulings of Islamic Law (Shari'ah) on currencies. To develop the understanding on what is the functions required in a currency to be compatible from an Islamic perspective. it is concluded that developing a Shari'ah 
compliant digital currency can be feasible soon since the presented cases in the research might be able to provide sufficient solutions to cover the current shortcomings of digital currencies regarding its practicality and compliance with Islamic functions of money and social objectives.

\section{References}

Abdullah, A. (2013). The Gibson paradox: Real gold, interest rates and prices. International Business Research, 6(4), 32. https://doi.org/10.5539/ibr.v6n4p32

Abdullah, A. (2016). The Islamic currency. Kuala Lumpur: International Council of Islamic Finance Educators.

Ali, R., Barrdear, J., Clews, R., \& Southgate, J. (2014). Innovations in payment technologies and the emergence of digital currencies, 271-272.

Babbitt, D., \& Dietz, J. (2014). Crypto-Economic Design: A Proposed Agent-Based Modeling Effort. In English. Conference Talk. University of Notre Dame, Notre Dame, USA.

Baxter, P., \& Jack, S. (2008). Qualitative case study methodology: Study design and implementation for novice researchers. The qualitative report, 13(4), 544-559.

Chapra, M. U. (1985). Towards a just monetary system (Vol. 8). International Institute of Islamic Thought (IIIT).

Cizakca, M. (2011). The Islamic gold dinar-Myths and reality. ISRA International Journal of Islamic Finance, 3(1), 49-63.

Danezis, G., \& Meiklejohn, S. (2015). Centrally banked cryptocurrencies. arXiv preprint arXiv:1505.06895.

Dyhrberg, A. H. (2016). Hedging capabilities of bitcoin. Is it the virtual Gold? Finance Research Letters, 16, 139-144. https://doi.org/10.1016/j.frl.2015.10.025

Evans, C. (2015). Bitcoin in Islamic Banking and Finance. Journal of Islamic Banking and Finance, 3(1), 1-11. https://doi.org/10.15640/jibf.v3n1a1

Gold vs. Bitcoin, Is bitcoin investment better than Gold investment? (n.d.). Retrieved May 12, 2017, from http://www.apmex.com/education/investing/gold-vs-bitcoin

Greco, A. (2009). On the economy of specialization and division of labor in Plato's Republic. Polis: The Journal for Ancient Greek Political Thought, 26(1), 52-72. https://doi.org/10.1163/20512996-90000142

Greco, T. (2009). The end of money and the future of civilization. Chelsea Green Publishing.

Kameel Mydin Meera, A., \& Larbani, M. (2006). Part I: Seigniorage of fiat money and the maqasid al-Shari'ah: the unattainableness of the maqasid. Humanomics, 22(1), 17-33. https://doi.org/10.1108/08288660610647774

Khaldūn, I. (1969). The Muqaddimah: an introduction to history; in three volumes. 1 (No. 43) P.336. Princeton University Press.

Lim, E. G., \& Sriram, S. (2003). Factors underlying the definitions of broad money: An examination of recent US monetary statistics and practices of other countries.

Mainelli, M., \& Smith, M. (2015). Sharing ledgers for sharing economies: an exploration of mutual distributed ledgers (aka blockchain technology). The Journal of Financial Perspectives, 3(3), 38-69.

Maurer, B., Nelms, T. C., \& Swartz, L. (2013). "When perhaps the real problem is money itself!": the practical materiality of Bitcoin. Social Semiotics, 23(2), 261-277. https://doi.org/10.1080/10350330.2013.777594

Mujani, W. K., Yaacob, S. E., Nasohah, Z., Kusrin, Z. M., \& Samuri, M. A. A. (2012). Gold dinar as a supreme currency: Review based on the history of Islamic civilization. Advances in Natural and Applied Sciences, 6(3 SPECL. ISSUE 2), 348-356.

Nakamoto, S. (2008). Bitcoin: A peer-to-peer electronic cash system.

Omar, M. N. (2011). The Islamic view on money and its implication for financial instruments. ISRA International Journal of Islamic Finance, 3(1), 161-167.

Samuel, H. W. (2017). "Seven Ways to Compute the Relative Value of a U.S. Dollar Amount, 1774 to present," Measuring Worth, April 2017.

Singhal, A., \& Rafiuddin, A. (2014). Role of Bitcoin on Economy. In Proceedings of the World Congress on Engineering and Computer Science (Vol. 2).

Taymiyyah, I. (1963). Majmu Fatawa Shaykh al-Islam Ahmad ibn Taymiyyah, 29/251, Riyad: 
Matabe'al-Riyad, 1382, 8.

USD inflation rate Calculator. Retrieved August 5, 2017, from https://www.calcxml.com/calculators/bud12

Van Alstyne, M. (2014). Why Bitcoin has value. Communications of the ACM,57(5), 30-32. https://doi.org/10.1145/2594288

Zahudi, Z. M., \& Amir, R. A. T. R. (2016). Regulation of Virtual Currencies: Mitigating the Risks and Challenges Involved. Journal of Islamic Finance, 5(1), 63-73. https://doi.org/10.12816/0027653

\section{Copyrights}

Copyright for this article is retained by the author(s), with first publication rights granted to the journal.

This is an open-access article distributed under the terms and conditions of the Creative Commons Attribution license (http://creativecommons.org/licenses/by/4.0/). 